\title{
Formação acadêmica, Educação e Sociedade
}

\author{
Formación científica, Educación y Sociedad
}

Education, Education and Society

Me. Everton Fêrrêr de Oliveira ${ }^{1}$

Dra. Ana Cristina Rodrigues da Silva Rodrigues ${ }^{2}$

Lucas da Silva Martinez ${ }^{3}$

Kelly Souza de Lima ${ }^{4}$

\begin{abstract}
Resumo
O texto aborda reflexões do Grupo de Trabalho Formação Acadêmica, Educação e Sociedade proposto para o II Encontro Humanístico Multidisciplinar, trouxe em seu entorno a discussão acerca da educação sob múltiplos aspectos, compreendendo as políticas públicas, universidade, práticas educacionais, imaginário social, história e memória. Também possibilitou por em relevo as práticas dos programas complementares na formação acadêmica. Trabalhos de ensino, pesquisa e extensão que dialoguem sobre novas perspectivas nas Ciências humanas, bem como o Programa de Educação Tutorial - PET e o Programa Institucional de Bolsa de Iniciação à Docência - PIBID, o Programa Idiomas sem Fronteiras - IsF entre outros. Como conclusão colaborou com seus participantes no adensamento de questões e diálogos sobre suas práticas e produções no território brasileiro, bem como suas fronteiras, os diferentes níveis e contextos educacionais, pensando como esses atuam e de que forma contribuem na formação educacional e superação de desafios.
\end{abstract}

Palavras-Chave: Formação Acadêmica, Educação e Sociedade

\section{Resumen}

El texto trata de reflexiones del Grupo de Trabajo de Formación Científica, Educación y Sociedad propuestos para la Segunda Reunión Multidisciplinar Humanista llevados en sus alrededores la discusión sobre la educación bajo múltiples aspectos, incluida la política pública, la universidad, las prácticas educativas, imaginario social, la historia y memoria. También permitió a las prácticas de alivio de programas complementarios en la formación académica. trabajos de enseñanza, investigación y extensión que se comunican sobre nuevas perspectivas en las ciencias humanas, y el Programa de Educación Tutorial - PET y el Programa Institucional de Iniciación de subvención para la enseñanza - PIBID los Idiomas Sin Fronteras Programa - ISF entre otros. En conclusión colaborado con los participantes en la densificación de las preguntas y el diálogo sobre sus prácticas y producciones en el territorio brasileño y sus fronteras, los diferentes niveles y contextos educativos, pensando cómo funcionan y cómo contribuyen a los desafíos de la educación y la superación.

\footnotetext{
${ }^{1}$ Mestre em Educação; Universidade Federal do Pampa - Unipampa; Jaguarão, Rio Grande do Sul, Brasil; evertonoliveira@unipampa.edu.br.

${ }^{2}$ Doutora em Educação; Universidade Federal do Pampa - Unipampa; Jaguarão, Rio Grande do Sul, Brasil; anacristinarodrigues@unipampa.edu.br

${ }^{3}$ Licenciado em Pedagogia, mestrando em Educação - Universidade Federal de Santa Maria, Santa Maria, Rio Grande do Sul, Brasil; lukasspedagogia@gmail.com

${ }^{4}$ Graduanda em Pedagogia; Universidade Federal do Pampa - Unipampa; Jaguarão, Rio Grande do Sul, Brasil; kelly23lima@ hotmail.com
} 

e-ISSN 2016/Atual: 2525-7870 | e-ISSN 2015/2016: 2447-018X

Palabras claves: Formación Científica; Educación; Sociedad.

\section{Abstract}

The text deals with reflections of the Working Group on Education, Education and Society proposed for the II Multidisciplinary Humanistic Meeting, brought in its surroundings the discussion about education in multiple aspects, including public policies, university, educational practices, social imaginary, history and memory. It also made it possible to highlight the practices of complementary programs in academic formation. Teaching, research and extension work that discusses new perspectives in human sciences, as well as the Tutorial Education Program - PET and the Institutional Program of the Initiative for Teaching - PIBID, the Languages without Borders Program - IsF among others. As a conclusion, he collaborated with his participants in the broadening of questions and dialogues about their practices and productions in the Brazilian territory, as well as their borders, the different educational levels and contexts, thinking about how they act and how they contribute to educational formation and overcoming challenges.

Key words: Academic Formation, Education and Society

\section{Introdução}

Dentre os artigos apresentados, que compuseram o GT3 "Formação Acadêmica, Educação e Sociedade", todos versaram a interdisciplinaridade e estudos humanísticos, fator principal em discussão no âmbito do evento.

Ao observar os múltiplos olhares neste GT, no âmbito do ensino, pesquisa e extensão, trago considerações acerca das temáticas discutidas nos dias do evento. Alias, temáticas estas, desafiadoras, das mais variadas, trazendo a tona discussões acerca da interculturalidade, identidade cultural, territorialidades, cidadania, identidade cultural, inclusão, formação docente, relatos de práticas docentes, programas de iniciação científica, estágios supervisionado, análises institucionais, entre outros muitos que caberá ressaltar ao longo deste escrito.

No decorrer dos encontros do grupo, as discussões foram perpassadas por alguns conceitos trazidos pelos autores, sinalizamos alguns neste exercício de análise, sem contudo esgotá-los pois tivemos sessenta e uma submissões neste grupo, nossos esforços em analisar esta vivência formativa certamente não traduz a efetiva participação e exposição de pontos de vista e acontecimentos dos cotidianos escolares da formação acadêmica aqui socializados.

\section{Exercício de Análise: diálogos acerca do conhecimento produzido na formação}

O GT Formação Acadêmica, Educação e sociedade reuniu produções sob diferentes perspectivas que buscaram profundas reflexões sobre o contexto da educação e sua relação com a sociedade. 
Radicalizado na verticalidade das relações proporcionadas em encontros com o perfil do II Encontro Humanístico Multicultural o GT foi formado por alunos de graduação, pósgraduação latu senso, stricto senso professores da educação básica, professores universitários e, pesquisadores das mais diversas áreas. Além disso contou com temáticas e trabalhos advindos de esferas como a realização do ensino na graduação e pós-graduação, extensão, pesquisa e programas complementares como Programa Institucional de Iniciação à Docência (PIBID), Programa de Educação Tutorial (PET) , Programa Idiomas sem Fronteiras suas contribuições, impactos e aprendizagens nos mais diversos contextos e movimentos sociais e educacionais.

A tônica do GT se destacou pela significativa ampliação da perspectiva da formação acadêmica onde a produção artesanal e coletiva do conhecimento se coloca em oposição a uma concepção produtivista que impregna em tempos contemporâneos os espaços acadêmicos. Nesta perspectiva uma das primeiras reflexões que se coloca diz respeito ao fato de que a formação acadêmica atual, de forma geral, está baseada em um projeto geopolíico em ruptura com a realidade da América Latina.

Os trabalhos debatidos no GT sejam eles relatos de práticas realizadas no PIBID, em estágios de docência, em projetos de intervenção de Mestrados Profissionais em Educação, em projetos de pesquisa problematizaram políticas educativas e econômicas que organizam o urbano e o consumo a partir da lógica americana e europeia sem um olhar profundo para o momento de profunda contradição no qual mergulha o contexto latino americano. Os conflitos na relação público privado e na relação escola e sociedade vieram a tona nas diversas experiências debatidas pelo grupo, marcando trajetórias de diferentes gerações.

Um representativo número de trabalhos analisa as situações de vulnerabilidade da infância e da juventude problematizando as formas como a educação e a escola tem servido como suporte para a formação e/ ou possibilidade de transformação da condição social destas diferentes infâncias e juventudes.

As pesquisas e trabalhos apresentados demonstraram a formação de uma outra juventude a partir das múltiplas vivências de infância, indicando a formação poliglota de uma nova geração, as formas como "as juventudes" tem estabelecidos outras posturas frentes ao saber tal como nos diz Charlot (2000, 2001, 2002), onde, o mesmo procura “(...) compreender qual é o tipo de relação com o mundo e com o saber que a criança deve construir, com a ajuda da escola, para ter acesso ao pleno uso das potencialidades escondidas na mente humana" (CHARLOT, 2002, p.65). 
A perspectiva da relação com o saber tem levado a reflexão sobre as formas como o mundo juvenil entra em conflito com o mundo escolar. Tal reflexão se estende inclusive as perspectivas universitárias quando se depara com movimentos estudantis tais como as ocupações que levam a profundos debates sobre reorganização dos currículos e das relações institucionais.

Em tempos de conflito os diferentes grupos sociais acentuam a necessidade do debate político na relação entre as instituições educativas: escolas, universidades, institutos e a sociedade, todavia é evidente que não se nasce como ser político. O ser político se constrói nas relações sociais, culturais e históricas. É preciso, no devir histórico produzir outras epistemologias que comportem a superação do caráter binário da ciência, que permitam romper e ampliar outras fronteiras, pois a construção ou a produção do conhecimento do objeto implica o exercício da curiosidade epistemológica, sua capacidade crítica de tomar distancia do objeto, de observá-lo, de delimitá-lo, de cindi-lo, de "cercar" o objeto ou fazer aproximações metódicas, sua capacidade de comparar, de perguntar (FREIRE, 1996, p. 85).Ocorre que a fragilidade dos tempos atuais tem trazido a sensação de que nos tornamos reféns da própria humanidade, uma vez que os "infernos" são vistos sempre a partir da relação dos outros e nos outros. Nesta lógica a troca realizada nas experiências dos trabalhos acentuou a importância da partilha entre escola, universidade comunidade!

$\mathrm{Na}$ perspectiva da multidisciplinaridade e da internacionalização apontada pelo encontro se destacam os trabalhos sobre o estatuto da fronteira. Os relatos sobre viagem realizada ao longo de toda fronteira sul articulando as reflexões sobre a arquitetura e a pedagogia da viagem retratam o processo de construção de uma fronteira que mais une do que separa. A construção histórica da fronteira sul da américa latina marcando as relações entre Brasil, Uruguai e Argentina vão permitindo um novo olhar sobre as relações de pertencimento, de construção de identidades sobre o lugar. Assim educar e educar-se fazem parte dos territórios, das ações, das vivências. Concordamos com Boaventura De Souza Santos (2011) quando realiza consideração a cerca da universidade e nossa ação caminha pela percepção de um conhecimento pluriuniversitário. Além disso, lutamos pelo direito ao acesso ao conhecimento de todos os seres humanos, a compreensão de que a extensão universitária "devem manter o apoio solidário na solução dos problemas da exclusão e da discriminação social e de tal modo que nele se tenha voz aos grupos excluídos e discriminados" (p.74).

Tais trajetórias, sejam nas viagens pedagógicas, sejam nos encontros, seminários, conferências programados, planejados e dialogados por bolsistas, pesquisadores, professores técnicos, sejam nos movimentos de lutas, como ocupações, plenárias, debates o que marca o 
caráter educativo é a processualidade, a historicidade, a discursividade com que vão se constituindo sujeitos e experiências. Especialmente porque não estamos tratando da Pedagogia restrita a formação de professores, por que

(...)Vivemos numa era, em que a transitoriedade do conhecimento impera marcada pelo mundo multifacetado, com mudanças substanciais nas diferentes dimensões sociais, econômicas, políticas, culturais, em uma época que relativiza as noções de espaço e tempo. É necessário focar o olhar e problematizar noções tradicionais que conhecemos de Pedagogia e ampliar as discussões para um campo que envolva zonas fronteiriças, que transgridam a ordem estabelecida, e se preciso for, pedir ajuda a outros campos do saber, tomar de empréstimo de outros campos disciplinares (ROVARIS e WALKER, 2012, p.10-11)

Ai está posto o desafio da formação acadêmica, da educação e da construção de uma nova sociedade. A busca educativa, neste sentido está em uma educação que busque formas alternativas e criativas para que as diferentes vozes sejam ouvidas

Ao referir essas temáticas, fazemos destaque a algumas intensas discussões realizadas. Exemplo disso seriam a interculturalidade, assunto este, extremamente discutido na esfera dos estudos Culturais em Educação, concomitante a globalização e multiculturalismo e a nossa formação, nossa identidade cultural, que segundo Candau (2012, p.25), "a primeira reforçando a padronização e o segundo as particularidades culturais e as diferenças". Realmente a globalização perpassa nossa atualidade, não existem muros principalmente para a globalização econômica, as mídias, a tecnologia, etc.

Quanto à interculturalidade, esta vem apostando nas relações entre grupos sociais e étnicos, assim, "enfrenta a conflitividade inerente a essas relações. Favorecendo os processos de negociação cultural, a constituição de identidades de 'fronteira', 'híbridas', plurais e dinâmicas, nas distintas dimensões da dinâmica social. O que impede que sigam reforçando a forma que a mídia coloca a produção cultural não só juvenil, mas infantil, ou seja, o mais monolítica possível. Cabe a escola estimular o diálogo, as trocas em que a bagagem cultural dos alunos seja respeitada, valorizada bem como permita que esses se apropriem de bens culturais diferentes. Pois,

A educação intercultural aponta uma solução ao problema que se apresenta nas sociedades multiculturais, já que se refere a uma relação ativa entre culturas para chegar a desenvolver uma sociedade intercultural. Portanto, este tipo de educação põe ênfase nos pontos de contato e no diálogo que se deve produzir entre as culturas, sempre em um clima de igualdade e respeito. Desta perspectiva, e ressaltando esta relação de entendimento e consenso, também se produz uma inter-relação profunda entre as minorias, que são 
portadoras do diversidade cultural, e a sociedade em que se encontram que pode representara cultura majoritária (AGUILAR, 1998:08).

Momentos como este são importantes para a socialização e a valorização do trabalho de todos os envolvidos, e porque não para a formação da identidade, pois para HALL (2005, p. 38), esta é,

realmente algo formado, ao longo do tempo, através de processos inconscientes, e não algo inato, existente na consciência no momento do nascimento.Existe sempre algo "imaginário" ou fantasiado sobre sua unidade. Ela permanece sempre incompleta, está sempre "em processo", sempre "sendo formada".

Nessa ampla perspectiva, Candau (2012, p. 51), destaca que vem apostando nas relações entre grupos sociais e étnicos, "enfrenta a conflitividade inerente a essas relações. Particularmente, um trecho marcou nossas discussões:

é importante que as práticas educativas partam do reconhecimento das diferenças presentes na escola e na sala de aula, o que exige romper com os processos de homogeneização, que invisibilizam e ocultam as diferenças, reforçando o caráter monocultural das culturas escolares. Romper com este daltonismo cultural e ter presente o arco-íris das culturas. (CANDAU, 2012, p.129-30)

Outra questão discutida durante os encontros, aspecto bem relevante foram sobre as diferenças culturais. Diante disso, entendemos que as diferenças são inventadas num processo contínuo de construção e desconstrução, constitutivas dos sujeitos e dos grupos sociais. As diferenças devem reconhecidas e valorizadas, pois nelas estão as marcas de identidade.

Trabalhar as diferenças culturais constitui o foco central do multiculturalismo. A diferença não te problemas nenhum, a não ser quando está presente a discriminação, a exclusão. Nesse sentido a perspectiva intercultural é situada ao meio de conceitos como cultura, identidade cultural, diferença, diversidade cultural, identidades de fronteira, hibridização cultural, entre outros.

Atualmente as diferenças culturais vêm sendo discutidas nos mais diversos espaços, sendo afirmadas nas práticas pedagógicas. A necessidade de trabalhar as diferenças culturais nas escolas é fundamental, referindo e esclarecendo os conceitos de cultura e diferença, os quais ainda não estão extremamente claros aos alunos.

Durante o evento, refletimos sobre questões relativas à interculturalidade e ao multiculturalismo, sobre o preconceito, a discriminação versus sociedade, escola, levando em consideração a urgência em trabalhar questões no cotidiano a fim de reconhecer e valorizar as 
diferenças culturais nas escolas. É preciso levantar questões que os alunos trazem de casa, refletem e reproduzem na escola, mas ainda acredita-se na escola porque o aluno passa o maior tempo nela, ou seja, desafiar a educação escolar, trabalhar a questão das diferenças que é um componente configurador de sua própria realidade; as diferenças negadas, silenciadas, naturalizadas ou reduzidas são constitutivas da prática pedagógica. Afirmamos acima necessidade de ressignificar a perspectiva crítica no âmbito da educação e da didática, favorecendo um processo de reconfiguração em que se propõem a educação brasileira.

Dentre o diálogo entre professores, estudantes e pesquisadores, discorreu-se sobre a necessidade permanente de refletir sobre nossas práticas pedagógicas diárias, nas escolas, nas universidades, levando em consideração o trabalho com questões de valorização, visto que que somos profundamente modificados socioculturalmente, com valores, culturas e identidades sendo constituídos culturalmente, fato que está extremamente relacionado aos eixos discutidos, que contribuem na formação educacional.

\section{Conclusões}

Realmente é preciso sair do seu espaço, vivenciar novas experiências para que ao retornar tenhamos não só adquirido novos conhecimentos, mas ampliando nosso campo de visão e percepção, nosso espaço. É nos colocando no lugar do outro que nos enxergamos melhor.

Contudo, a tarefa não é simples, requer o envolvimento de todos, cada um fazendo sua parte em busca de bons resultados. Para além de ficarmos sentados escutando teorias, muitas vezes vazias, as oficinas, encontros, conversas, nos levaram ao movimento, a conhecermos um pouco de trabalhos que vem sendo realizados em compromisso com a nossa educação brasileira. Nestes momentos foram construídos mais que conhecimentos, mas cumplicidade, parcerias.

As discussões partem de uma ótica que problematizam os paradigmas científicos e filosóficos que demandam o rompimento com uma compreensão binária imposta pela racionalidade moderna, as discussões enaltecem um novo olhar sobre o mundo, um olhar integro sobre as relações em sociedade e meio ambiente. Este temário sobre a Formação Acadêmica, Educação e Sociedade é e tem sido foco de muitos encontros, fóruns, conferências e demais espaços de construções coletivas, contando com a participação de representantes e militantes em busca de novos rumos visando minimizar as problemáticas decorrentes das ações da humanidade problematizando o desenvolvimento econômico e social. 
Terminamos o ano de 2016 com esperanças de que 2017 seja ainda mais repleto de ensinamentos e aprendizagens, sempre com intuito de fazer a diferença, em qualquer que seja o espaço de aprendizagem, dentro ou fora dos muros da escola ou da universidade! Para finalizar, vale ainda dizer, que acreditamos que o poder de transformar está nos homens e torna-se visível na sua incansável busca pela liberdade. E é neste sentido, que o pensar e o agir de maneira crítica, viabilizam o aparecimento de um novo tempo na educação, capaz de potencializar a emancipação dos homens.

\section{Referências bibliográficas}

AGUILAR, J. J. E. Controvérsias en torno a Ia Educación Multicultural [on-line] Disponível na internet via URL http://www2.ucaes/HEURESIS/heuresis98/v1 n2-3.htm (acesso em 13 agosto de 2015).

CANDAU, Vera Maria (Org.). Didática Crítica Intercultural: Aproximações. Rio de Janeiro: Editora Vozes, 2012.

CHARLOT, B. Relação com a escola e o saber nos bairros populares. Revista Perspectiva, v.20, n. Especial, Jul/Dez 2002

HALL, Stuart. A identidade cultural na pós-modernidade. 10a ed. Rio de janeiro: dp\&a; 2005.

FREIRE, P. Pedagogia da Autonomia: saberes necessários á prática educativa. São Paulo: Paz e Terra, 1996

ROVARIS, N. A. Z. e WALKER, M. R. Formação de professores: Pedagogia como Ciência da Educação. In: IX Seminário de Pesquisa em Educação da Região Sul, IX ANPED Sul. Universidade de Caxias do Sul, Caxias do Sul - RS, 2012. Disponível em: http://www.ucs.br/etc/conferencias/index.php/anpedsul/9anpedsul/paper/viewFile/525/640 (acesso em 02 de novembro de 2016)

SANTOS, B. de S.. A universidade no século XXI: Para uma reforma democrática e emancipatória da universidade/ Boaventura de Souza Santos- 3.ed- São Paulo: Cortez, 2011. Disponível em: http://www.ces.uc.pt/bss/documentos/auniversidadedosecXXI.pdf (acesso em 16 de dezembro de 2016) 